\title{
A mulher no corpo: considerações sobre a homogeneidade e os paradoxos da perspectiva feminista
}

\author{
VANESSA MAIA RANGEL •
}

\author{
MARTIN, Emily. \\ A mulher no corpo: uma análise cultural da reprodução \\ Tradução: Júlio Bandeira. \\ Revisão técnica e apresentação: Fabíola Rohden \\ Rio de Janeiro: Garamond, 2006. 384 p.
}

O livro A mulher no corpo: uma análise cultural da reprodução traz uma abordagem de Emily Martin que parece fazer parte do que Sandra Harding (1987) chamou de ponto de vista feminista. Este não é propriamente uma metodologia ou uma epistemologia, mas uma abordagem que se origina de experiências femininas, feita geralmente por mulheres pesquisadoras engajadas numa luta política. Dentro desta concepção, esse ponto de vista não seria uma aclamação, mas uma conquista, necessária para ver a natureza e a vida social do ponto de vista das atividades desprezadas, que produzem as experiências sociais das mulheres.

A importância da abordagem de Emily Martin expressa nesse livro se caracteriza pelo que Harding (1987) chama de falta de reconhecimento da autoridade feminina em termos do conhecimento; o que, segundo a autora, legitimaria o lugar de uma ciência social feminista. Esta se concretiza principalmente por análises empíricas, que têm a intenção de refletir o mundo a nossa volta de forma menos distorcida e incompleta do que a ciência social tradicional, incluindo, assim, o ponto de vista das mulheres pesquisadoras.

Embora seja parte desta mesma ciência a crítica quanto à unicidade da perspectiva feminista, já que pode não intencionalmente subjugar as questões de raça/etnia, classe e cultura, por outro lado pretende demonstrar que as mulheres se encontram geralmente no lugar dos saberes subjugados - de fato, que as mulheres estão nos locais onde ocorrem as diferenças.

Entendendo, portanto, a perspectiva da autora, o texto resenhado vai indicar as principais idéias da sua obra num sentido mais descritivo, e apontar 
especialmente para o caráter paradoxal de determinadas análises que a autora faz a partir de seus dados empíricos. A intenção não será resolver esses paradoxos, mas levantar a possibilidade de serem componentes estruturais das análises feministas.

Na introdução à edição de 1992 a autora esclarece seu ponto de partida: de que as mulheres compartilham um corpo entendido como biológico, evidenciado nos processos fisiológicos da menstruação, parto e menopausa. Seu enfoque se constrói nos incidentes de resistência, em que as mulheres discordam dos discursos médico-científicos associados a seus corpos. Assim a autora propõe que a coleta das experiências a partir de situações vivenciadas corporalmente possa criar uma identidade feminina alternativa.

No capítulo "O familiar e o exótico", a autora define sua motivação pelo seu treinamento como antropóloga, utilizando uma metodologia de pesquisa baseada em entrevistas com mulheres de diferentes faixas etárias, classes sociais e raça/etnia. As entrevistas foram feitas, em sua maioria, nas residências das próprias entrevistadas, por mulheres pesquisadoras de semelhantes características socioeconômicas e etárias.

A análise das entrevistas se deteve na comparação entre as representações femininas e o discurso médico-científico, acerca dos processos biológicos do corpo feminino - em particular, à implicação das metáforas apresentadas nos textos médicos em relação à organização das experiências femininas.

Definindo essa focalização, Martin analisa como os textos médicos desde o século XIX mostram um entendimento das mulheres a partir de uma dicotomia, onde os mundos "natural", doméstico, dominado e conseqüentemente feminino foram vistos como análogos e incompletos. Além da dicotomia, é evidente uma fragmentação da pessoa, sobretudo um entendimento do corpo como uma máquina a ser consertada; ignorando, portanto, sua dimensão relacional. A autora confere que essa maneira de pensar o corpo feminino se deve a uma alienação da ciência e da produção do conhecimento científico, ligada à objetividade e outros valores, que a autora aponta como masculinos.

Martin enfatiza, neste momento, que o objetivo do livro seria definir um confronto relativo ao discurso biológico, onde as representações culturais por esses textos apresentadas, serão questionadas pelas representações femininas das entrevistadas. Martin se interessa particularmente em saber se as mulheres conhecem e como reagem ao reducionismo, à dicotomia, à fragmentação e ao 
empobrecimento de suas vidas (especialmente seus corpos) por estas representações biológicas; e que consciências alternativas podem emergir a partir de suas considerações.

Em "Metáforas médicas no corpo da mulher: menstruação e menopausa", a autora coloca como a idéia dos corpos análogos presente até o século XVIII foi substituída pela concepção mais científica de dois corpos diferentes e de dois papéis sociais tradicionais que estes implicavam. A importância da mudança é que dentro dessa dicotomia o corpo feminino foi associado a metáforas negativas e patológicas. A partir deste marco, o corpo em geral foi associado a um sistema de controle hierarquizado verticalmente, onde os hormônios fazem papel de comunicadores circulantes de retroalimentação; no caso feminino, esse sistema foi resumido a cérebrohormônios-ovários, definindo um sistema de comunicação análogo ao que seriam as formas de comportamento dominante da sociedade da época.

Ainda na questão metafórica da literatura médica, a autora analisa a visão da menopausa como uma ruptura deste processo de resposta à autoridade cerebral, entendida como "falência". Tal concepção de falência serviria como um indicador indireto de que esse sistema hormonal hierárquico feminino estaria voltado para uma certa produção virtuosa. Martin critica esta objetividade naturalizada, presente nos textos médicos, com o exemplo biológico oposto: o da menstruação (constrição, desintegração, fragmentação, perda, necrose). $\mathrm{Ou}$ seja, mostra que o que é visto como objetivo também fracassa. A menstruação seria, portanto, o lado negativo deste processo produtivo, um espaço onde a mulher se encontra fora do controle dessa hierarquia.

Segue-se um questionamento da razão pela qual eventos fisiológicos como menstruação e menopausa não poderem ser considerados protetores, ou seja, aponta para "um certo tipo" de interpretação que foi adequada aos fatos. A autora busca, a partir das representações das experiências femininas, caminhos alternativos para entender esses processos fisiológicos dos seus corpos, sugerindo a eliminação da hierarquia e a abertura para a possibilidade de múltiplos objetivos associados a esses processos biológicos.

No capítulo sobre o parto, Martin analisa como a metáfora médica da produção fabril vai gerenciar o entendimento sobre o contexto do parto. Neste caso, o útero é visto como um instrumento de produção e o parto um trabalho mecânico a ser monitorado. Dentro desta expectativa, o papel da mulher se torna secundário e ambíguo, ora auxiliando o trabalho uterino involuntário, ora 
atrapalhando o andamento do processo mecânico. Enquanto isso, o trabalho obstétrico é descrito como condutor do processo fabril de produzir bebês perfeitos. Este mecanismo, segundo a autora, aumenta o controle sobre o corpo da mulher e sobre o número de intervenções sobre seus corpos. A análise de Martin define que este excesso de controle e o enfoque no bebê ignoram a experiência feminina e suscita comportamentos de revolta, demonstrados em alguns exemplos que a autora apresenta.

Este ponto do livro de Martin apresenta o primeiro paradoxo da sua análise feminista. Há uma supervalorização da questão da resistência aos valores ditos dominantes, e ênfase na possibilidade de revolta. Não há nenhuma menção ao "potencial de altruísmo" feminino, em conceder sua experiência em troca do bebê saudável. Ou seja, os exemplos resistentes de Martin mostram uma naturalização na "escolha" pelo bebê.

O paradoxo em relação ao parto continua a se desenvolver no capítulo seguinte: imagem do eu no corpo, onde Martin concebe que suas entrevistadas apresentam argumentos que espelham, de forma fragmentada, o encontrado nos manuais médicos. Por outro lado, no caso de intervenções com direcionamento médico definido (como as cesarianas), os argumentos apontam para experiências frustrantes, de ruptura de expectativas, falta de controle e fragmentação por parte das mulheres.

As experiências que Martin aborda demonstram a impressão do evento do parto não ser sobre mulheres, apenas através de seus corpos. Demonstram também como, muitas vezes, as mulheres se sentem desligadas de seus recémnascidos após um parto que não se sentiram realizando. Esse espelhamento em relação ao discurso médico, encontrado até nas representações daquelas que lutam pela saúde da mulher, é, na visão de Martin, produto da invisibilidade e da tenacidade dessas idéias e práticas. A autora analisa que este seria o motivo de não se encontrar maior grau de resistência, apenas uma sensação de algo errado; e um esforço torturante para conciliar a experiência com as expectativas médicas.

Já em relação à menstruação, Martin coloca que a inserção feminina na dinâmica do trabalho fora de casa faz com que as mulheres "encorporem" a noção deste processo biológico como chato, ingrato ou trabalhoso. Por outro lado, a autora analisa que lugares fechados, de uso íntimo como os banheiros, são atuados como locais de subversão e de rompimento das normas. Nesta avaliação da utilização dos locais mais íntimos, Martin parece prosseguir com o paradoxo feminista, pois essa possível subversão feminina, quando usa o banheiro, 
pode ser também uma certa obediência, já que espaços privados sempre foram tradicionalmente espaços de autonomia feminina.

A questão principal que aparece nos exemplos do bom trabalho empírico de Martin não é a procurada resistência, mas sim a solidariedade expressa nas falas das entrevistadas. Além disso, aparece também a questão da rotina do trabalho que não concebe o descanso público, determinando a procura de lugares mais íntimos, onde o encontro de experiências semelhantes promove a solidariedade já mencionada.

Retornando à menstruação, Martin encontra um outro lado desse processo biológico. Seus achados também mostram que este faz parte da vida, podendo definir o que é ser mulher e o poder reprodutivo a ela associado. Aqui Martin parece encontrar o dado em comum que une as mulheres entrevistadas, ou seja, a identidade feminina a partir desta biologia corporal. Embora a autora atente para a concepção de uma identidade única, ela contextualiza que as diferentes classes sociais e de raça/etnia conferem impressões diversas em relação a estes processos biológicos. As impressões são especialmente conflitantes em relação à reprodução, o que não acontece com a menstruação, que para Martin seria o processo biológico de união e de expressão da identidade procurada.

Em síndrome pré-menstrual, Martin explicita um desejo seu: que é produto da análise das experiências femininas quando referentes ao conflito rotina de trabalho versus tensão pré-menstrual. Martin coloca que freqüentemente a necessidade/desejo de adaptação à vida moderna por parte das mulheres é frustrada, encenando emoções de raiva e irritabilidade, sendo que estas são geralmente vistas como anormais. Tal anormalidade no comportamento feminino durante o período de tensão pré-menstrual é assinalada por Martin como um exemplo da visão de desajuste ao esperado papel harmônico das mulheres dentro das relações sociais. A autora critica que a visão do processo como um desajuste ou um distúrbio acaba resultando em tratamentos médicos para adequar a mulher ao seu suposto papel original, diminuindo a possibilidade de uma ressignificação não-patológica do processo.

A "encorporação" deste argumento médico faz com que a tensão prémenstrual seja vista pelas mulheres como um acontecimento que toma seus corpos; estes atingem um estado de descontrole e fragmentação do eu, interferindo nas atividades do cotidiano que passam a ser menos toleradas. Martin analisa que tal descontrole demonstrado através da raiva, sinaliza que certos papeis sociais desempenhados pelas mulheres as sobrecarregam e as 
responsabilizam. Martin retorna com a colocação de um desejo, apontando que a raiva só poderia ser vista como positiva se representasse parte da consciência coletiva da posição estrutural das mulheres na sociedade. Ela conclui, no entanto, que a participação através do gênero social é negada.

No capítulo sobre parto e as formas de resistência, Martin exemplifica algumas maneiras como as mulheres se rebelam contra a estrutura que as oprime, colocando como o exemplo mais extremo, a mulher que se recusa a ir ao hospital e resolve ter o filho(a) em casa. Esta revolta se deve ao papel secundário e pouco valorizado atribuído à mulher em relação à importância atribuída ao bebê; e que tem na tecnologia da monitoração do parto um elemento a mais de exclusão dessa experiência feminina. Dentro desta categoria de exclusão, Martin contextualiza que as mulheres de classes sociais mais baixas e étnico/raciais mais desprivilegiadas têm geralmente menos condições de resistir ao gerenciamento do discurso e das práticas médicas. Esta falta de resistência é, como já mencionado acima, mais visível durante a gestação e o parto.

Apesar desta constatação, Martin escreve o capítulo seguinte destinado a pensar sobre a possibilidade da criação de um novo imaginário do parto. Confere a necessidade da expressão de metáforas diferentes da fábrica e da produção, na organização de uma experiência do parto a partir de uma perspectiva feminina. A autora utiliza as palavras "dança" e "jornada", metáforas que indicam agir e experienciar. No entanto, não fica claro se tal colocação é também um desejo pertinente à perspectiva de Martin, ou se está calçada nos seus exemplos empíricos.

$\mathrm{Na}$ chegada da menopausa, as entrevistadas de Martin demonstram um sentido de constrangimento sem a conotação de doença. As entrevistas de Martin são privilegiadas no sentido de encontrar que outros fatores nãobiológicos, como a noção de envelhecimento, as mudanças dos contextos familiares e o aspecto de classe social, raça/etnia, podem auxiliar o entendimento desta fase como incômoda. Além disso, Martin aponta que à própria estrutura lingüística parecem equivaler determinados termos de conotação emocional: o calor e as mulheres aparecem em posições subordinadas.

Mas, surpreendentemente, a maioria dos relatos femininos descreve a menopausa apenas como algo que acabou; referindo-se à menstruação sem a conotação de falência. No seu extremo, sendo percebido como um processo fora de controle (por mulheres jovens) ou como um alívio (por mulheres mais velhas) pela ausência do medo da gravidez. Em comum às mulheres, em relação 
à vivência da menopausa, estariam a sensação de mudança, os reencontros, a liberação pública e os novos potenciais.

Agora passamos para o capítulo de classe e resistência, onde Martin aborda respostas femininas que se posicionaram contra a ideologia médicocientífica. A autora recolheu seis tipos de respostas: aceitação, lamentação, recusa de agir, sabotagem, resistência e rebelião, sendo a penúltima categoria valorizada pela autora e presente tanto nas classes médias quanto nas trabalhadoras. Embora a definição das categorias de oposição ao discurso médico seja definitivamente interessante e expresse as experiências de muitas mulheres em relação aos seus eventos fisiológicos, a maneira da abordagem das entrevistas de Martin, neste aspecto, parece incentivar respostas compatíveis com os valores feministas da pesquisadora.

Para entender e concluir esta abrangência das resistências, Martin aponta que embora as mulheres tenham "encorporado" grande parte dos conceitos científicos que denigrem seus corpos, suas experiências servem como subsídios que confrontam, através de suas histórias pessoais e coletivas, os fatos apresentados. Esta "encorporação" é, portanto, contraditória e ambígua, e recorre frequentemente à luta para o alcance da dignidade e autonomia. Estas características, por sua vez, estariam relacionadas às próprias experiências femininas menos permeadas pela dicotomia, nas quais nítidas separações e oposições não estariam presentes.

A autora afirma então, ser a luta política necessária para a conscientização e/ou existência da uma experiência feminina que diverge do discurso médico-científico. Para Martin, isto não implica necessariamente reforma social e revolução, mas indica o caráter compartilhado da experiência das mulheres na administração de seus corpos.

Aqui finalizamos, portanto, com nossa proposta de apontar para os paradoxos do trabalho de Martin, pois se são exatamente as mulheres que tradicionalmente inseridas em atividades concretas, administram o corpo social, além de seus próprios corpos e de suas famílias, como Martin concebe que elas se sintam administradas? 


\section{Referência}

HARDING, S. Introduction: Is There a Feminist Method? In: (Ed.).

Feminism and Methodology. Indianapolis: Indiana University Press, 1987.

\section{NOTA}

- Doutoranda no Instituto de Medicina Social da UERJ; na área de Política, Planejamento e Administração de Saúde; bolsista do CNPq. Endereço eletrônico: tufaha@ terra.com.br. 